\title{
Last-Minute Bidding and the Rules for Ending Second-Price Auctions: Evidence from eBay and Amazon Auctions on the Internet
}

\author{
By Alvin E. Roth and Axel Ockenfels*
}

Auctions on the Internet provide a new source of data on how bidding is influenced by the detailed rules of the auction. Here we study the second-price auctions run by eBay and Amazon, in which a bidder submits a reservation price and has this (maximum) price used to bid for him by proxy. That is, a bidder can submit his reservation price (called a proxy bid) early in the auction and have the resulting bid register as the minimum increment above the previous high bid. As subsequent reservation prices are submitted, the bid rises by the minimum increment until the second-highest submitted reservation price is exceeded. Hence, an early bid with a reservation price higher than any other submitted during the auction will win the auction and pay only the minimum increment

\footnotetext{
* Roth: Harvard University, Department of Economics and Graduate School of Business Administration, Soldiers Field Road, Baker Library 183, Boston, MA 02163 (e-mail: aroth@hbs.edu; URL: http://www.economics.harvard.edu/ aroth/alroth.html); Ockenfels: Max Planck Institute for Research into Economic Systems, Strategic Interaction Group, Kahlaische Strasse 10, D-07745 Jena, Germany (e-mail: ockenfels@mpiew-jena.mpg.de; URL: http://www.mpiew-jena.de/esi/ockenfels/index.html). We gratefully acknowledge helpful conversations on this subject with Estelle Cantillon, Scott Cook, Jeff Ely, Ed Glaeser, Seungjin Han, Ehud Kalai, Bertrand Koebel, Eric Maskin, Muriel Niederle, Martin Osborne, Ariel Pakes, Jack Porter, Jean-Francois Richard, Uri Rothblum, Hal Varian, and comments from audiences at the following universities and colleges: Berkeley, Berlin, Bielefeld, Bilbao, Bonn, Columbia, Dortmund, Harvard, Koblenz, London School of Economics, Minnesota, Munich, Northwestern, Stanford, and Wellesley. We also thank two anonymous referees for very helpful comments, the many bidders who allowed us to interview them, and the readers of a New York Times column by Hal Varian and a Wall Street Journal article by Joel Rosenblatt that mentioned an earlier version of this paper for many stimulating opinions. Most of the work was done while Ockenfels was a postdoctoral research fellow at the Harvard Business School. This project received financial support from the National Science Foundation, the Harvard Business School, and the Deutsche Forschungsgemeinschaft (DFG).
}

above the second-highest submitted reservation price.

eBay and Amazon use different rules for ending an auction. Auctions on eBay have a fixed end time (a "hard close"), while auctions on Amazon, which operate under otherwise similar rules, are automatically extended if necessary past the scheduled end time until ten minutes have passed without a bid. These different rules give bidders more reason to bid late on eBay than on Amazon. We find that this is reflected in the auction data: the fraction of bids submitted in the closing seconds of the auction is substantially larger in eBay than in Amazon, and more experience causes bidders to bid later on eBay, but earlier on Amazon.

Last-minute bidding, a practice called "sniping," arises despite advice from both auctioneers and sellers in eBay that bidders should simply submit their maximum willingness to pay, once, early in the auction. For example, eBay instructs bidders on the simple economics of second-price auctions, using an example of a winning early bid. They discuss last-minute bids on a page explaining that they will not accept complaints about sniping, as follows: ${ }^{1}$

Bid Sniping (last-minute bidding).

eBay always recommends bidding the absolute maximum that one is willing to pay for an item early in the auction. eBay uses a proxy bidding system: you may bid as high as you wish, but the current bid that is registered will only be a small increment above the next lowest bid. The remainder of your Maximum Bid is held, by the system, to be used in the event someone bids against you ... Thus, if one is outbid, one should be at worst, ambivalent toward being outbid. After all, someone else was simply willing to pay

\footnotetext{
${ }^{1}$ Online: 〈http://pages.ebay.com/aw/notabase.html (1999).
} 
more than you wanted to pay for it. If someone does outbid you toward the last minutes of an auction, it may feel unfair, but if you had bid your maximum amount up front and let the proxy bidding system work for you, the outcome would not be based on time.

Sellers, when urging potential buyers to bid early, are concerned that very late bids run the risk of not being successfully transmitted, which causes lower expected revenues. The following paragraph, posted by a seller (Axis Mundi) together with item descriptions, is representative advice:

\section{THE DANGERS OF LAST-MINUTE BIDDING: Almost without fail after an auction has closed we receive e-mails from bidders who claim they were at- tempting to place a bid and were unable to get into eBay. There is nothing we can do to help bidders who were "locked out" while trying to place a "last minute" bid. All we can do in this regard is to urge you to place your bids early. If you're serious in your intent to become a winning bidder please avoid eBay's high traffic during the close of an auction. It's certainly your choice how you handle your bidding, but we'd rather see you a winner instead of being left out during the last-minute scramble.}

Other warnings about late bidding come from auctionwatch.com, a rich source of information for users of Internet auctions ("There are inherent risks in sniping. If you wait too long to bid, the auction could close before your bid is processed") ${ }^{2}$ and from esnipe.com, an online agent that places late bids on behalf of its users (“... network traffic and eBay response time can sometimes prevent a bid from being completed successfully. This is the nature of sniping"). ${ }^{3}$ Despite all this advice, however, there is an active exchange of tips in eBay's chat rooms about how to snipe effectively, and there is even a market for bidding software that makes sniping easy. The following excerpt from a software ad reflects the inclination to bid late:

\footnotetext{
2 Online: http://www.auctionwatch.com/awdaily/ tipsandtactics/buy-bid2.html (2000).

${ }^{3}$ Online: http://www.esnipe.com/faq.asp (2000).
}

... our bidding program BidMaster 2000 provides you complete control. ... Set a bid 7 days ahead, track the item's price during the week, edit your bid time, and amount; when the end of the auction nears WHAM your bid will be placed automatically.

One reason we might see snipers on eBay is that sniping can be a best response to a variety of strategies. For example, inexperienced bidders might make an analogy with first-price "English" auctions, and be prepared to continually raise their bids to maintain their status as high bidder. In an eBay-style auction with a hard close, bidding very late might be a best response to "incremental bidding" of this sort. That is, bidding very near the end of the auction would not give the incremental bidder sufficient time to respond, and so a sniper competing with an incremental bidder might win the auction at the incremental bidder's initial, low bid. In contrast, bidding one's true value early in the auction, when an incremental bidder is present, would win the auction only if one's true value were higher than the incremental bidder's, and in that case would have to pay the incremental bidder's true value. Of course, late bidding may also be a best response to other incremental bidding (or "price war") behaviors, including that of a dishonest seller who attempts to raise the price by using "shill bidders" to bid against a proxy bidder. ${ }^{4}$ So, in an eBay auction, even with purely private values, it is not a dominant strategy to bid one's true value early, which might be suggested by false analogy to one-time sealed-bid second-price auctions. ${ }^{5}$

The advantage that sniping confers in an auction with a fixed deadline is eliminated or greatly attenuated in an Amazon-style auction with an automatic extension. ${ }^{6}$ In such an auc-

\footnotetext{
${ }^{4}$ Dan Ariely et al. (2002) provide lab evidence for incremental-bidding behavior in second-price Internet auctions. See Judith H. Dobrzynski (2000) in the New York Times or Glenn R. Simpson (2000) in the Wall Street Journal for well-publicized examples of shill bidding.

${ }^{5}$ A related observation, the failure of the dominance criterion in English-auction models, has been made in a theoretical contribution by Ulrich Kamecke (1998).

${ }^{6}$ The relevant Amazon rules are the following: "We know that bidding may get hot and heavy near the end of many auctions. Our Going, Going, Gone feature ensures that you always have an opportunity to challenge last-second bids.
} 
tion, an attentive incremental bidder can be provoked to respond whenever a bid is placed. So there is no advantage in bidding late, and certainly no advantage in delaying one's bid until so late that there is some probability that there will not be time to successfully submit it.

In fact, sniping in an auction with a fixed deadline, in which very late bids have some probability of not being successfully transmitted, need not depend on the presence of irrational bidders. There can be equilibria even in purely privatevalue auctions in which bidders have an incentive to bid late, even though this risks failing to bid at all. This kind of equilibrium can be interpreted as a kind of implicit collusion against the seller, because it has the effect of probabilistically suppressing some bids, and hence giving higher profits to the successful bidders. ${ }^{7}$ But in Amazon-type auctions, in which a successful late bid extends the auction, this kind of equilibrium does not persist (see Ockenfels and Roth [2002] for precise statements and proofs).

Another way to explain late bidding without positing inexperience or irrationality on the part of the bidders is to note that, if an auction is common value rather than private value, bidders can get information from others' bids that causes them to revise their willingness to pay. In general, late bids motivated by information about common values arise either so that bidders can incorporate into their bids the information they have gathered from the earlier bids of others, or so bidders can avoid giving information to others through their own early bids. In an auction with a fixed deadline, a sharp form of this latter cause of late bidding may arise when some bidders are better informed than others. For example, in auctions of antiques, there

Here s how it works: whenever a bid is cast in the last ten minutes of an auction, the auction is automatically extended for an additional ten minutes from the time of the latest bid. This ensures that an auction can't close until ten 'bidless' minutes have passed. The bottom line? If you're attentive at the end of an auction, you'll always have the opportunity to vie with a new bidder" (online: http://www.amazon.com/ exec/varzea/ts/help/going-going-gone/

002-3341436-6525260, 1999).

${ }^{7}$ The probability that some late bids will not be successfully transmitted is a risk for each bidder, but a benefit for his opponents, and it is this "public good" aspect of the risk of bidding late that creates the possibility of a profitable collusive late-bidding equilibrium in eBay (but not in Amazon). may be bidders who are dealers/experts and who are better able to identify high-value antiques. These well-informed bidders (who may be identifiable because of their frequent participation) may wish to bid late because other bidders will recognize that their bid is a signal that the object is unusually valuable. Bidding just before the deadline of an auction with a fixed deadline allows them to profit from their information without allowing other bidders enough time to respond. Again, in an Amazon-type auction with an automatic extension, the ability to bid without providing information to attentive competitors would be eliminated or substantially attenuated. ${ }^{8}$

Thus there are a variety of rational, strategic reasons for sniping (i.e., for bidding very near the scheduled end of an eBay auction), despite the risk that late bids may not be transmitted successfully. It is a best response to naïve incremental-bidding strategies, and can arise even at equilibrium in both private-value and common-value auctions. ${ }^{9}$

\footnotetext{
${ }^{8}$ This is the intuition reflected in the following bit of advice to bidders: "The greatest advantage of sniping is it affords you anonymity among the other bidders. If you're a long-time bidder, others who bid on the same items as you will recognize your user ID. Some might even 'ride your coattails,' performing site searches on what you're bidding on, then perhaps bidding against you. If you choose to snipe, the other bidders won't know where you'll strike next, and that can mean more wins and frequently better prices for you" (online: http:// www.auction watch.com/awdaily/tipsandtactics/buy-bid2. html, 1999; see Ockenfels and Roth [2002] for a more formal treatment that captures this intuition).

${ }^{9}$ Esnipe.com, a site that offers to automatically place a predetermined bid a few seconds before the end of the eBay auction, nicely summarizes some of these reasons but also speaks to the risks involved: "There are many reasons to snipe. A lot of people that bid on an item will actually bid again if they find they have been outbid, which can quickly lead to a bidding war. End result? Someone probably paid more than they had to for that item. By sniping, you can avoid bid wars. That's not all. Experienced collectors often find that other bidders watch to see what the experts are bidding on, and then bid on those items themselves. The expert can snipe to prevent other bidders from cashing in on their expertise.... Will esnipe guarantee that my bids are placed? We certainly wish we could, but there are too many factors beyond our control to guarantee that bids always get placed" (online: http://www. esnipe.com/faq.asp 2000). In fact, esnipe.com recently started to publish statistics on success rates, time to place bids and hourly trends based on an average of more than 4,200 bids per day (online: esnipe.com/stats.asp, 2000). While the time it takes to place a bid varies considerably over weekdays and hours, on average 4.5 percent of esnipe's late bids failed to be successfully transmitted in September 2000. (Esnipe was sold
} 
Table 1 -Hypotheses About the Causes of Late Bidding

\begin{tabular}{l}
\hline Hypotheses \\
Strategic hypotheses \\
Rational response to naïve English-auction behavior \\
or to shill bidders: bidders bid late to avoid \\
bidding wars with incremental bidders \\
Collusive equilibrium: bidders bid late to avoid \\
bidding wars with other like-minded bidders \\
Informed bidders protecting their information \\
(e.g., late bidding by experts/dealers) \\
Nonstrategic hypotheses \\
Procrastination \\
Search engines present soon-to-expire auctions first \\
Desire to retain flexibility to bid on other auctions \\
offering the same item \\
Bidders remain unaware of the proxy bidding system \\
Increase in the willingness to pay over time (e.g., \\
caused by an endowment effect) \\
Bidders do not like to leave bids "hanging"
\end{tabular}

Predicted contribution to late bidding

All three strategic hypotheses suggest more late bidding on eBay than on Amazon, with a bigger effect for more experienced bidders. Also (via the third point), more late bidding in categories in which expertise is important than in categories in which it is not.

No difference between eBay and Amazon.

Of course, there can also be nonstrategic reasons why bidders bid late, some of which are listed in Table 1. These nonstrategic reasons, however, should be relatively unaffected by the difference in rules between eBay and Amazon. (The hypotheses are not mutually exclusive; they could each be contributory causes of late bidding.)

The strategic differences between eBay-style (hard close auctions) and Amazon-style (automatic extension) auctions suggest that the hypotheses about the causes of late bidding can be investigated by examining the timing of bids on eBay and Amazon. So, we compare the timing of bids in eBay and Amazon in the categories Antiques and Computers, which might reasonably be expected to have different scope for expert information. We also survey late bidders on eBay to shed light on the observed behavior.

\section{Description of the Data Sample}

Amazon and eBay publicly provide data about the bid history and other features of auctions that have been completed within the last four weeks on eBay and eight weeks on Amazon. We downloaded data from both auction

on ebay in an auction ending at 18:08:38PST on 12/1/00, and the winning bid of $\$ 35,877.77$ arrived at 18:08:24 PST on $12 / 1 / 00$ along with three other bids that were submitted in the last minute.) sites in the categories "Computers" and "Antiques." In the category of Computers, retail prices of most items are easily available, because most items are new. ${ }^{10}$ Each bidder's willingness to pay, however, remains private information. In the Antiques category, retail prices are usually not available and the value of an item is often ambiguous and sometimes requires an expert to appraise. So the bids of others are likely to convey information about the item's value, allowing the possibility that experts may wish to conceal their information.

Our data set consists of randomly selected auctions completed between October 1999 and January 2000 that met certain selection criteria. ${ }^{11}$ For the category Computers we selected computer monitors and laptop auctions. For Antiques, we did not restrict our search to a particular subset of items. This is partly to avoid the danger that the data are dominated by atypical behavioral patterns that might have evolved in thin markets for specific antiques, and partly

${ }^{10}$ We did not collect data about retail prices, which would depend on many details of each item offered for sale.

${ }^{11}$ Most importantly, auctions were only included if they attracted at least two bidders, and auctions with a hidden reserve price were only considered if the reserve price was met. In this paper, we focus on our main results; a much more detailed account of the sampling criteria and of the data, including the distributions of number of bidders per auction and feedback numbers across auction houses, can be found in Ockenfels and Roth (2002). 
because of a lack of data on Amazon, since relatively few antiques are auctioned there. In total, the data from 480 auctions with 2,279 bidders were included in all analyses of this paper. We have 120 eBay Computers with 740 bidders, 120 Amazon Computers with 595 bidders, 120 eBay Antiques with 604 bidders, and 120 Amazon Antiques with 340 bidders. $^{12}$ For each auction, we recorded the number of bids, number of bidders, and whether there was a reserve price. On the bidder level, we recorded the "timing" of the last bid and each bidder's "feedback number." Both variables are described in detail next.

Both auction houses provide information about when each bidder's last bid is submitted. ${ }^{13}$ For each bidder we downloaded how many seconds before the deadline the last bid was submitted. (If the bid came in before the last 12 hours of the auction end, we just count this bid as "early"). While this information is readily provided in eBay's bid histories of completed auctions, the end time of an auction in Amazon is endogenously determined since an auction continues past the initially scheduled deadline until ten minutes have passed without a bid. We therefore computed for each last bid in Amazon the number of seconds before a "hypothetical" deadline. This hypothetical deadline is defined as the current actual deadline at the time of bidding under the assumption that the bid in hand and all subsequent bids were not submitted. ${ }^{14}$

\footnotetext{
${ }^{12}$ eBay maintains a substantially bigger market than Amazon (see David Lucking-Reiley [2000] for a comprehensive survey of internet auctions, their sizes, revenues, institutions, etc.). For instance, on the supply side, the number of listed items that we found for our Computers category exceeds Amazon's number in the same time span by a factor of about ten. There may be other differences besides volume, since buyers as well as sellers self-select themselves into an auction. Following the data analysis, we will argue that this selection might influence the magnitude of the differences between Computers and Antiques within an auction format, but should not influence the direction of the differences we report.

${ }^{13}$ Since October 2000, eBay's bid history for each auction includes all bids.

${ }^{14}$ Suppose, for example, one bid comes in one minute before the initial closing time and another bidder bids eight minutes later. Then, the auction is extended by 17 minutes. The first bid therefore is submitted 18 minutes and the second bid ten minutes before the actual auction close. The
}

On eBay, buyers and sellers can give each other positive feedback $(+1)$, neutral feedback $(0)$, or negative feedback $(-1)$ along with a brief comment. A single person can affect a user's feedback number by only one point (even though giving multiple comments on the same user is possible). The total of positive minus negative feedback is eBay's "feedback number." It is prominently displayed next to the bidder's or seller's eBay username. Amazon provides a related, slightly different reputation mechanism. Buyers and sellers are allowed to post 1-5 star ratings of one another. Both the average number of stars and the cumulative number of ratings are prominently displayed next to the bidder's or seller's Amazon username. We refer to the cumulative number of ratings as the "feedback number" on Amazon. Since in both auction sites the feedback numbers (indirectly) reflect the number of transactions, they might serve as approximations for experience and, more cautiously, as an indicator of expertise. ${ }^{15}$

\footnotetext{
bids show up in our data, however, as one and two minutes (before the hypothetical deadline), respectively. Since we only observe the timing of last bids, this calculation implicitly assumes that no bidder bids more than once later than ten minutes before the initial deadline. The potential effect of this bias is, however, very small. In total, 28 out of 240 Amazon auctions in our sample were extended. In 26 of these auctions, only one bidder and in the other two auctions two bidders bid within the last ten minutes with respect to the initial deadline. Therefore, we may misrepresent the timing of up to 30 out of 935 Amazon bidders. Note that the possible misrepresentation of timing with respect to the hypothetical instead of the actual closing time leads us, if at all, to overestimate the extent to which Amazon bidders bid late. This would only strengthen our comparative results of late bidding in Amazon and eBay.

${ }^{15}$ Note that the feedback number on eBay is the sum of positive and negative feedback. Hence, if positive and negative feedbacks were left with comparable probabilities, the feedback numbers could not be interpreted as experience or expertise. The fact, however, that in our eBay sample no bidder (but two sellers) had a negative feedback number while more than 25 percent have zero feedback numbers indicates that negative feedbacks are left very rarely. This suggests that both the feedback numbers in eBay and Amazon are proxies for the number of transactions. Other authors empirically examine the effect of feedbacks in eBay on price (Daniel Houser and John Wooders, 2000; Lucking-Reiley et al., 2000; Mikhail I. Melnik and James Alm, 2001), on the emergence of trust (Paul Resnick and Richard Zeckhauser, 2001; see also Gary Bolton et al. [2002] for a related experimental study), and on multiple bidding (Ockenfels and Roth, 2002).
} 

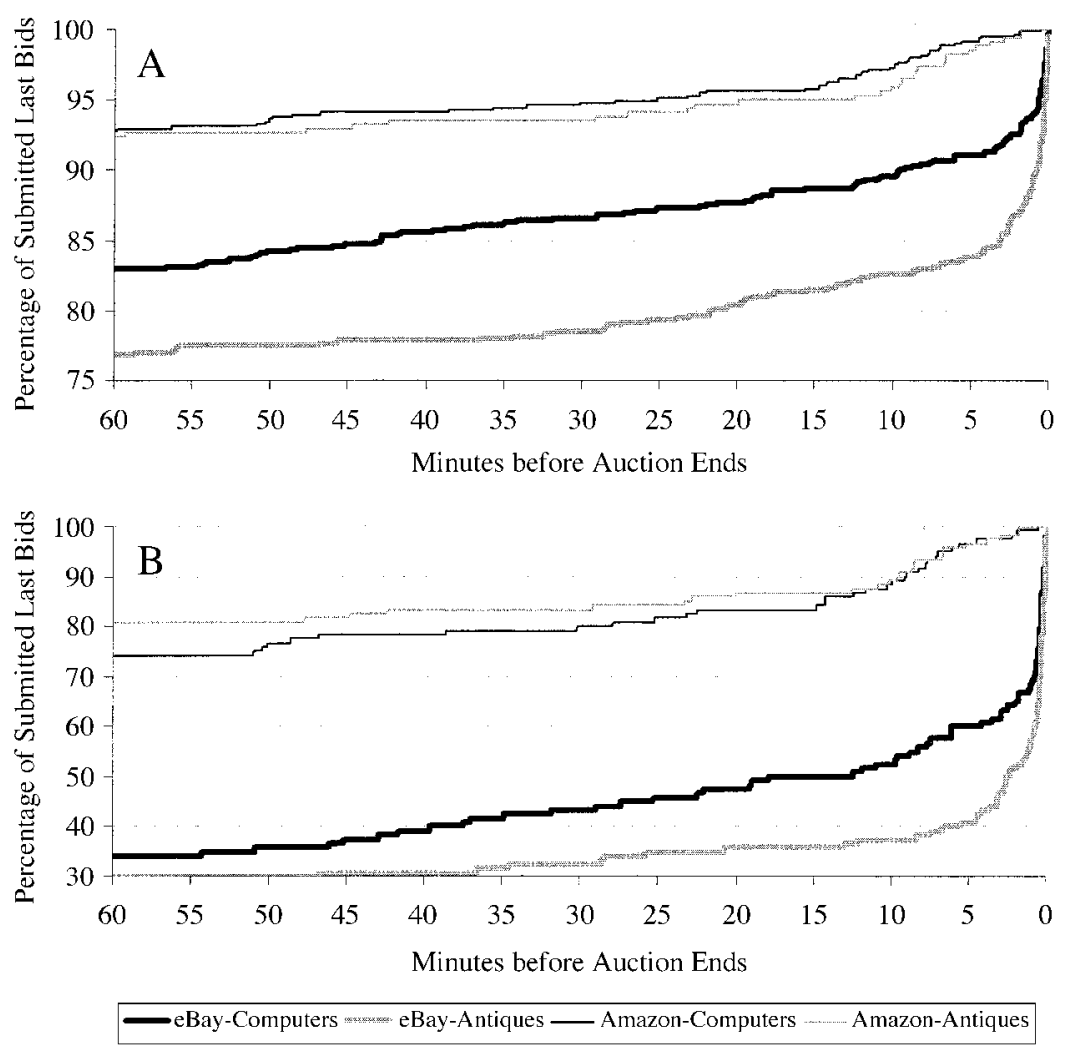

Figure 1. Cumulative Distributions over Time of (A) Bidders' Last Bids and (B) Auctions' Last Bids

\section{The Timing of Bids}

Figure 1 illustrates our central observations regarding the timing of bids. Figure 1A shows the empirical cumulative probability distributions of the timing of last bids for all bidders, and Figure 1B the corresponding graphs for only the last bid in each auction. ${ }^{16}$ The graphs

\footnotetext{
${ }^{16}$ Recall that the timing of bids in Amazon is defined with respect to a "hypothetical" deadline that differs from the actual closing time if a bid comes in later than ten minutes before the initial end time. Recall also that the last bidder is not necessarily the high bidder since an earlier submitted proxy bid can outbid subsequent incoming bids. Specifically, in eBay $29(89,132,163)$ final bids but only 17 $(66,106,131)$ winning bids were submitted within the last ten seconds (one minute, ten minutes, one hour). In Amazon the corresponding frequency distributions of final and winning bids are $(0,1,28,54)$ and $(0,0,20,43)$, respectively. We finally note here that it is not too unusual to see the auction price in eBay double in the last 60 seconds, and since it takes some seconds to make a bid, bidders attempt-
}

show that in both auction houses, a considerable share of last bids is submitted in the very last hour of the auctions. (Recall that the auctions usually run for several days.) However, late bidding is substantially more prevalent on eBay than on Amazon.

Figure 1A reveals that 20 percent of all last bids on eBay compared to 7 percent of all last bids on Amazon were submitted in the last hour. Figure 1B shows that in more than two-thirds of all eBay auctions, at least one bidder is still active in the last hour, while this is only true for about one-quarter of all Amazon auctions. Furthermore, the graphs reveal that, on eBay, a

ing to submil a bid while the price is rising so rapidiy may receive an error message telling them that their bid is under the (current) minimum bid. These eBay bidders, who attempted to bid in the last minute, are not represented in these data, since their last-minute bids did not register as bids in the auction. 
considerable share of bidders submit their bid in the last five minutes ( 9 percent in Computers and 16 percent in Antiques), while only a few bids come in equally late on Amazon (about 1 percent in both Computers and Antiques). The difference is even more striking at the auction level: 40 percent of all eBay Computers auctions and 59 percent of all eBay Antiques auctions as compared to about 3 percent of both Amazon Computers and Amazon Antiques auctions, respectively, have last bids in the last five minutes. The pattern repeats in the last minute and even in the last ten seconds. ${ }^{17}$ In the 240 eBay auctions, 89 have bids in the last minute and 29 in the last ten seconds. In Amazon, on the other hand, only one bid arrived in the last minute. The figures also indicate that within eBay, bidders bid later in Antiques than in Computers. ${ }^{18}$

The main differences in the four distributions in each of the two graphs in Figure 1 (more late bidding in eBay than in Amazon in each category, respectively, and more late bidding in eBay Antiques than in eBay Computers) can be statistically supported by various regression analyses on both the bidder and the auction level. ${ }^{19}$ Furthermore, the regressions reveal an

${ }^{17}$ In fact, a more detailed theoretical and econometric analysis of the full shape of the distributions in Roth and Ockenfels (2000) reveals that the distributions of the timing of bids in Amazon and eBay are strikingly self-similar. That is, it is virtually impossible to say whether a distribution of last bids is drawn from, say, the last hour or from the last 12 hours of the auctions if no information about the time scale is given.

${ }^{18}$ As pointed out by a referee, the timing shown in Figures 1A and 1B cannot be explained by the "naïve" hypothesis that more bidders per auction cause last bids to be later. In fact, Figure 1B shows that last bids in eBay Computers come earlier than last bids in eBay Antiques, while the number of bidders per auction is actually significantly higher in eBay Computers (see Ockenfels and Roth, 2002).

${ }^{19}$ In Roth and Ockenfels (2000), we ran probit, logit, and ordinary least-squares (OLS) regressions using 5-, 10-, and 15-minute thresholds for late bidding, while controlling for the number of bidders per auction and bidders' feedback numbers. All differences in the distributions mentioned above are statistically significant at the 5-percent level (twosided), while no statistically significant difference between Amazon Antiques and Amazon Computers can be detected, independent of the statistical model or the threshold for late bidding. The results appear to be also robust across different data sets. First, in a pilot study, we downloaded data from eBay and Amazon in 320 auctions of computer monitors interesting correlation between bidders' feedback numbers and late bidding. The impact of the feedback number on late bidding is highly significantly positive in eBay and (weakly significantly) negative in Amazon. This suggests that more experienced bidders on eBay go later than less experienced bidders, while experience in Amazon has the opposite effect, as suggested by the strategic hypotheses. ${ }^{20}$ It is therefore safe to conclude that last-minute bidding is not simply due to naïve time-dependent bidding. Rather, it responds to the strategic structure of the auction rules in a predictable way. In addition, since significantly more late bidding is found in antiques auctions than in computer auctions on eBay but not on Amazon, behavior responds to the strategic incentives created by the possession of information, in a way that interacts with the rules of the auction.

Because these data do not come from a controlled experiment, self-selection of buyers and sellers into different auctions might affect some of our results. If expert antique buyers prefer to bid on eBay, and if sellers of goods that require expert valuation follow them to eBay, this might increase the size of the difference in late bidding between eBay Antiques and Computers, as compared to Amazon Antiques and Computers. (Of course the difference between late bidding on eBay for computers and for antiques would still support the prediction that there will be more late bidding on items that require expertise to evaluate.) The other personal variable that the theory predicts is important is experience in the sense of learning best responses, as distinct from acquiring expertise related to the items for sale. One might conjecture that the differences in the timing of bids between eBay and Amazon reflect differences

\footnotetext{
and antique books. The data set is tess complete since onty last bidders and only two feedback categories were considered. To the extent we can compare the data with the data reported in this paper, however, they agree in essentially all qualitative features described here. Second, in an exploratory sample of just over 1,000 eBay auctions with at least one bid in May and June 1999, we found substantial variation in the percentage of last-minute bids, ranging from 56 percent in the category "Antiques: Ancient World" to 0 percent in "Collectibles: Weird Stuff: Totally Bizarre."

${ }^{20}$ Ronald T. Wilcox (2000) examines a sample of eBay auctions and also finds that more experienced bidders bid later.
} 
in the distributions of bidders' experience (as described by Ockenfels and Roth [2002]). A selection bias of this sort cannot explain the fact, however, that the effect of experience on the timing of bids goes in the opposite directions on eBay and Amazon, as suggested by the strategic hypotheses. Furthermore, we think that the fact that all the strategic predictions are that there will be more late bidding on eBay than on Amazon diminishes the likelihood that the positive results for that comparison are primarily due to selection based on buyer and seller characteristics. But there is still room for a controlled experiment in the laboratory, which we will discuss further in the conclusion. ${ }^{21}$

\section{Survey}

Three hundred and sixty-eight eBay bidders who successfully bid at least once in the last minute of an auction were sent a questionnaire. We included approximately the same number of bidders who bid late in Computers and Antiques. Twenty percent responded to our survey. The survey complements the bid data, by giving bidders' perspectives about what drives late bidding, and by providing information about the (otherwise unobservable) risk that a late bid fails to be transmitted. We very briefly report some patterns in the answers. ${ }^{22}$

\footnotetext{
${ }^{21}$ Some of our experimenter colleagues have asked at seminars why, if there are unobserved parts of the field data, we did not start from the outset with an experimental investigation. The answer is that field studies and laboratory experiments are complements not substitutes, and as many questions would have been raised about a laboratory study. If late bidding had been observed (only) in the lab, the natural question would be whether it arose because subjects who were already in the lab until the end of the experiment paid no cost to wait and bid at the last minute. Without a field study, it would have been reasonable to conjecture that the same effect would not be observed in the field, in bidding by people who have other things to do than wait for auctions to end.

${ }^{22}$ Not all bidders answered all questions. The percentages we report here refer to the actual number of answers to the corresponding question. See Roth and Ockenfels (2000) for the complete questionnaire and a collection of typical answers to each question. Note also that the fact that late bidders tend to be more experienced is reflected in our survey sample. The average feedback number in our eBay choice data is 29 for all bidders and 64 for all last-minute bidders. The average feedback number in our survey data is 83 .
}

A large majority of responders (91 percent) confirm that late bidding is typically part of their early planned bidding strategy. Most of these bidders unambiguously explain that they snipe to avoid a "bidding war" or to keep the price down. In addition, some experienced Antiques bidders (about 10 percent of all responders, mostly with high feedback numbers) explicitly state that late bidding enables them to avoid sharing valuable information with other bidders. $^{23}$ At the same time, some bidders say that they are sometimes influenced by the bidding activity of others, although 88 percent of the late bidders in our survey say that they have a clear idea, early in the auction, about what they are willing to pay. But besides this supportive evidence for strategic late bidding, we also find some indications of naïve late bidding. A few bidders (less than 10 percent, mostly with zero feedback number) appear to confuse eBay with an English auction (i.e., they appear to be unaware of eBay's proxy bidding system). ${ }^{24}$

Although more than 90 percent of the responders to our survey never use sniping software, many operate with several open windows and synchronize their computer clock with eBay time in order to improve their late-bidding performance. Nevertheless, when bidding late, 86 percent of all bidders report that it happened

\footnotetext{
${ }^{23}$ Here are three examples of responses from Antiques bidders: "I know that certain other parties will always chase my bid" (feedback number = 649); "I do so in part because I have found that when I bid early I tend (nearly always) to be outbid, even if I put in a high bid. Maybe this is because I am thought to have special knowledge about what is a good item (e.g., due to my books)" (182); "The most difficult part is ascertaining the genuineness of a particular piece. If it is fake then I lost the game and my knowledge was inadequate. This is where it is important not to bid early on an item. If you are well known as an expert and you bid, then you have authenticated the item for free and invite bidding by others" (47).

${ }^{24}$ One bidder explains his late bidding as follows: "Because I will then know if the price is low enough for the item" (feedback number $=0$ ); another bidder writes: "I would also be sure that other bidders wouldn't outbid me" (0). Interestingly, some more experienced bidders realize that beginners are particularly impatient when bidding: "Many new buyers are particularly aggressive in making sure they are listed as high bidder" (198); "The newbies want only to win and will bid until their money runs out, another reason to wait until the last 30" (43); "If there are first-time bidders ( 0 ) then it's best to walk away. They will push the price up just to stay the high bidder" (6).
} 
at least once to them that they started to make a bid, but the auction was closed before the bid was received. But there is another prevalent risk of late bidding: about 90 percent of all bidders say that sometimes, even though they planned to bid late, something came up that prevented them from being available at the end of the auction so that they could not submit a bid as planned. Most bidders gave a quantitative estimation about how often this happened to them. The median response is 10 percent for each kind of risk.

\section{Conclusions}

Theoretical considerations suggest that the rule for ending an auction can affect bidding behavior long before the end. The clear difference observed in the amount of late bidding on eBay and Amazon is strong evidence that, as predicted both at equilibrium and when some bidders are unsophisticated, the hard close gives bidders an incentive to bid late, in both privateand common-value auctions. This evidence is strengthened by the observations that (i) the difference is even clearer among more experienced bidders, and (ii) there is more late bidding for eBay Computers than for eBay Antiques, reflecting the additional strategic incentives for late bidding in eBay auctions in which expertise plays a role in appraising values. The substantial amount of late bidding observed on Amazon, (even though substantially less than on eBay) suggests that there are also nonstrategic causes of late bidding, possibly due to naïveté or other nonrational cause, particularly since the evidence suggests that it is reduced with experience. $^{25}$

\footnotetext{
${ }^{25}$ Of course we do not claim to have exhausted the possible strategic and nonstrategic causes of late bidding in the brief list of hypotheses tested in this study. For example, late bidding in Amazon auctions can arise rationally to the extent that the last ten minutes is a sufficiently short interval so as to present a reduced probability of successful bidding. Preliminary studies (Neeraj Gupta, 2001) suggest that in auctions hosted by Yahoo!, in which the seller may choose either a hard close or an automatic five-minute extension, the effect of this choice on late bidding is less clear than the difference between eBay and Amazon auctions. Or perhaps the hard close provides greater entertainment value by concentrating so much of the bidding action at the very end of the auction. Thus, while we find multiple causes, our evi-
}

The size of the difference between bid distributions on eBay and Amazon suggests that the different rules for ending an auction is an important element of the auction design. ${ }^{26} \mathrm{On}$ the other hand, the limitations of field data mean that there is room for controlled experiments to help supply a detailed understanding of the difference. Amazon and eBay data reflect not only the behavior of individuals in different auctions, but possibly also the selfselection of individual buyers and sellers with different characteristics into the auctions, and different choices of alternative auctions. We have argued that these uncontrolled differences cannot account for all of the differences we observed, but in the laboratory these differences can be eliminated, and the auction rules compared cleanly. See Ariely et al. (2002) for an experiment that replicates the late-bidding comparisons found in our field data, under controlled conditions in a pure private-value environment. In that experiment, subjects are randomly assigned to different auction conditions, and bid for

\footnotetext{
dence is not inconsistent with the phenomena discussed by Patrick Bajari and Ali Hortaçsu (2000), Deepak Malhotra and J. Keith Murnighan (2000), and Wilcox (2000). The first two of those papers each looks at an auction of a particular commodity under a fixed set of rules and deduces that the late bidding they observe results from a particular cause (common values, and irrational "competitive arousal," respectively). The third paper looks at auctions of several commodities on eBay, and notes that experienced bidders tend to bid later. But because our empirical design (and our theoretical framework in Ockenfels and Roth [2002]) permits us to compare the auctions of dissimilar commodities using the same auction rules, and similar commodities using different auction rules, the common bidding behavior observed in all three studies can be viewed here in a broader perspective.

${ }^{26}$ The presence of multiple causes for the same phenomena means, however, that it remains difficult to unambiguously assess the effects of the different auction designs. For a fixed set of bidders for a given, privatevalue object, our findings suggest that a second-price auction with a hard close will raise less revenue than one with an automatic extension, because late bidding causes some bids to be lost. But our theoretical considerations also suggest that bidders with the expertise to identify valuable objects will prefer auctions with a hard close, because in this case late bidding allows the experts to protect their information. So the present evidence does not allow us to suggest which design should be preferred by sellers, although it suggests that the answer may depend on the kind of good being auctioned.
} 
identical, artificial commodities for which they are paid in cash by the experimenter according to values that they know when they bid. As remarked earlier, field studies and laboratory experiments are complements, not substitutes. The present study is a case in which multiple kinds of evidence (theory, transaction data, surveys, anecdotal quotes, experiments) all point in the same direction.

Now that economists are increasingly being called upon to design a variety of markets (see e.g., Roth and Elliott Peranson, 1999; Paul Milgrom, 2001; Roth, 2002; Robert Wilson, 2002), we need to be alert to the fact that small design differences can elicit substantial differences in behavior. ${ }^{27}$ In designing new markets, it will be important to consider not only the equilibrium behavior that we might expect experienced and sophisticated players eventually to exhibit, but also how the design will influence the behavior of inexperienced participants, and the interaction between sophisticated and unsophisticated players. The effect of the fixed deadline is no doubt as large as it is because it rewards late bidding both when other bidders are sophisticated and when they are not.

\section{REFERENCES}

Ariely, Dan; Ockenfels, Axel and Roth, Alvin E. "An Experimental Analysis of Ending Rules in Internet Auctions." Unpublished manuscript, Harvard University, 2002.

Bajari, Patrick and Hortaçsu, Ali. "Winner's Curse, Reserve Prices and Endogenous Entry: Empirical Insights from eBay Auctions." Working paper, Stanford University, 2000.

Bolton, Gary; Katok, Elena and Ockenfels, Axel. "How Effective Are Online Reputation Mechanisms? An Experimental Investigation." Working paper, Pennsylvania State University, 2002.

\footnotetext{
${ }^{27}$ In the design of the FCC auctions of radio spectrum, a concern that late bidding would interfere with efficient price discovery led to the inclusion of "activity rules" that prevented bidders from entering the auction only near the end (cf. Milgrom, 2001; Roth, 2002).
}

Dobrzynski, Judith H. "In Online Auctions, Rings of Bidders." New York Times, 2 June 2000 , p. 1.

Gupta, Neeraj. "Internet Auctions: A Comparative Study of Seller Options on eBay, Amazon, and Yahoo!" Undergraduate thesis, Harvard College, 2001.

Houser, Daniel and Wooders, John. "Reputation in Auctions: Theory and Evidence from eBay." Working paper, University of Arizona, 2000.

Kamecke, Ulrich. "Dominance or Maximin? How to Solve an English Auction." International Journal of Game Theory, October 1998, 27(3), pp. 407-26.

Lucking-Reiley, David. "Auctions on the Internet: What's Being Auctioned, and How?" Journal of Industrial Economics, September 2000, 48(3), pp. 227-52.

Lucking-Reiley, David; Bryan, Doug; Prasad, Naghi and Reeves, Daniel. "Pennies from eBay: The Determinants of Price in Online Auctions." Working paper, Vanderbilt University, 2000.

Malhotra, Deepak and Murnighan, J. Keith. "Milked for all Their Worth: Competitive Arousal and Escalation in the Chicago Cow Auctions." Working paper, Kellogg School of Management, Northwestern University, 2000.

Melnik, Mikhail I. and Alm, James. "Does a Seller's eCommerce Reputation Matter?" Working paper, Georgia State University, 2001.

Milgrom, Paul. "Auction Theory for Privatization." Unpublished manuscript, Stanford University, 2001.

Ockenfels, Axel and Roth, Alvin E. "Late Bidding in Second Price Internet Auctions: Theory and Evidence Concerning Different Rules for Ending an Auction.” Working paper, Harvard University, 2002.

Resnick, Paul and Zeckhauser, Richard. "Trust Among Strangers in Internet Transactions: Empirical Analysis of eBay's Reputation System." Draft prepared for National Bureau of Economic Research workshop, 2001.

Roth, Alvin E. "The Economist as Engineer." Econometrica, July 2002, 70(4), pp. 1341-78.

Roth, Alvin E. and Ockenfels, Axel. "Last Minute Bidding and the Rules for Ending Second-Price Auctions: Theory and Evi- 
dence from a Natural Experiment on the Internet." National Bureau of Economic Research (Cambridge, MA) Working Paper No. 7729, 2000.

Roth, Alvin E. and Peranson, Elliott. "The Redesign of the Matching Market for American Physicians: Some Engineering Aspects of Economic Design." American Economic Review, September 1999, 89(4), pp. 748-80.

Simpson, Glenn R. "Ebay Coin Auctions
Produce Allegations of 'Shill' Bidding." Wall Street Journal, 12 June 2000, pp. A3, A6.

Wilcox, Ronald T. "Experts and Amateurs: The Role of Experience in Internet Auctions." Marketing Letters, November 2000, 11(4), pp. 363-74.

Wilson, Robert. "Architecture of Power Markets." Econometrica, July 2002, 70(4), pp. 1299-1340. 